\title{
IS RISING EARNINGS INEQUALITY ASSOCIATED WITH INCREASED EXPLOITATION? EVIDENCE FOR U.S. MANUFACTURING INDUSTRIES, 1971-1996
}

\author{
ARTHUR SAKAMOTO \\ University of Texas at Austin \\ CHANGHWAN KIM \\ University of Kansas
}

\begin{abstract}
Is the trend towards rising earnings inequality associated with increased exploitation? The authors investigate exploitation among workers using data for manufacturing industries. Defined as the underpayment of earnings relative to productivity as evaluated in the market, exploitation is measured for various groups of employees. The results indicate significant levels of exploitation among women, Hispanics, African Americans, and blue-collar workers. By contrast, employees who are overpaid relative to their productivities include middle-aged workers, older workers, and managers. Additional findings suggest that the increase in inequality in recent years has been associated with heightened exploitation due to the underpayment of workers in the lowest two quintiles of the earnings distribution, while workers in the upper two quintiles have become increasingly overpaid. Rising earnings inequality in the manufacturing sector thus appears to be associated with increased exploitation when the latter is measured as the underpayment of market value to workers. A related analysis by Liu, Sakamoto, and Su also investigates patterns of economic underpayment and overpayment but does not link them explicitly to inequality in the distribution of earnings and how the level of inequality has been increasing in recent years.

Keywords: exploitation; earnings inequality; manufacturing industry
\end{abstract}

In an era of expanding inequalities, the failure to empirically measure exploitation remains a major - albeit rarely acknowledged-shortcoming of the study of social stratification (Kim and Sakamoto 2008a). Although ignored in contemporary sociology, the empirical investigation of exploitation is critically important. In addition to being relevant to public policy debates, exploitation is theoretically

Address correspondence to: Arthur Sakamoto, Department of Sociology, 1 University Station A1700, University of Texas, Austin, TX 78712-0118; e-mail: sakamoto@mail.la.utexas.edu.

Sociological Perspectives, Vol. 53, Issue 1, pp. 19-43, ISSN 0731-1214, electronic ISSN 1533-8673.

(c) 2010 by Pacific Sociological Association. All rights reserved. Please direct all requests for permission to photocopy or reproduce article content through the University of California Press's Rights and Permissions website, at http://www.ucpressjournals.com/reprintinfo.asp. DOI: 10.1525/sop.2010.53.1.19. 
significant in regard to the long-standing sociological concern for understanding the nature and consequences of inequality (Sørensen 2000; Wright 2000). If the higher earnings of some workers primarily reflect their greater efforts, skills, and consequent productivity, then the implications of this trend are much different than if it derives from monopolistic advantages that some employees utilize to extract salaries that are substantially higher than their productivities. Despite its importance, exploitation has not been adequately investigated by any sociologist using statistical data since the time of Karl Marx.

In the following, we derive and empirically investigate a measure of exploitation using data for U.S. manufacturing industries from 1971 to 1996. We define exploitation as the extent to which the earnings of various groups in the labor force are underpaid relative to the market value of their productivities. The primary substantive issue that we address is whether rising earnings inequality in the U.S. manufacturing sector is associated with increased exploitation. In order to illustrate how the empirical study of exploitation intersects with other major topics in social stratification, we extend our analysis to estimate variations in the level of exploitation across labor market groups defined in terms of gender, race, ethnicity, age, education, marital status, and occupational category.

In addition to developing an appropriate methodology, our more general objective is to spur further research on exploitation by demonstrating how its empirical investigation is entirely feasible as well as sociologically informative. More empirical research about exploitation is needed not only because it would provide additional findings about the sources of exploitation as operationalized here but also because other useful measures may be developed in the future by building upon our approach. In short, exploitation is an empirical phenomenon that is worthy of objective investigation.

\section{THE CONCEPTUAL BASIS FOR A MEASURE OF EXPLOITATION}

As discussed by Sakamoto and Liu (2006), different types of exploitation may be conceptualized that are not mutually exclusive. For this reason, different measures of exploitation may ultimately prove to be useful for empirical research. Just as there are different dimensions and measures of educational attainment, political attitudes, and family relations, several indicators of exploitation may eventually be needed. Our measure is not the only conceivable approach.

The concept of exploitation should be distinguished from the processes that are hypothesized to generate it. Recent debates have reached an intellectual quagmire. Sociologists concur that exploitation is an extremely important topic, but disagreements about its causes have dissuaded its empirical analysis. We caution against dismissing an intrinsically informative measure of exploitation on the grounds that it is not clearly identified with a broader theory. Systematic measurement typically precedes the scientific study of causal processes.

\section{Measuring Exploitation in the Labor Market}

A basic definition of exploitation is being paid less than the value of what one produces because someone else obtains the difference without providing adequate compensation for it. As stated by Sørensen (2000:1532), "exploitation is a question 
of economic advantage obtained at the expense of someone else." The essential idea is the payment of wages that, for a given time period, are less than the value added by workers because part of it is being diverted to another group of people who are benefiting from the appropriation. This generic definition seems broadly applicable to different descriptions of exploitation, although a consensus has yet to emerge regarding how to conceptualize the "value of what one produces" (Sakamoto and Liu 2006).

Modern capitalism is characterized by an extensive division of labor and complex production processes. In contrast to the production systems of pre-industrial societies in which an individual worker often produced much of the product that is sold or consumed, an individual worker in contemporary capitalism typically performs only a tiny subset of the total activities that are required in order to realize the sale of the product. The economic "value of what one produces" is difficult to measure at the level of the individual worker whose particular job activities alone do not yield a salable commodity.

In this context, we use a factors-of-production methodology to analyze the creation and measurement of economic value. This approach is appropriate because it recognizes the contributions of all of the various factors of production (i.e., capital, industry-specific technology, material supplies, energy costs, and the labor of different types of employees including managers) that are involved in the realization of the sale of the product which is a reasonable and direct indicator of its value. Our factors-of-production methodology uses data to empirically estimate the multivariate relationships between the value created and the quantities of the various inputs utilized in the production process.

Drawing upon contemporary economics, the marginal revenue product of a factor of production (e.g., capital or some type of labor) refers to the value added by that input given some level of output. In the case of a particular type of labor, the marginal revenue product refers to the revenue that is obtained from the sale of the additional product that is produced as the result of additional hours worked by that type of labor after taking into account the quantities of the other inputs that are used in the production process. This approach considers the total value of the output of the firm as a dependent variable that is determined by the quantities of the various factors of production including capital investments and specific types of labor input. The "value of what is produced by labor," on a per-unit basis, is then defined as the increment in the total output value that accrues by employing another unit of labor of a particular type, holding constant the other factors of production by way of the multivariate production function (i.e., the marginal revenue product for the given type of labor). Being based on aggregate data, however, this methodology identifies only averages at the level of the group and should not be construed to refer to any particular individual worker per se.

We then define exploitation as the underpayment of a particular category of workers relative to its marginal revenue product. That is, when the earnings for a given group of employees is less than their value added, then the difference between these two quantities represents an underpayment that we define as exploitation. Exploitation would not exist (i.e., it would be equal to zero) were the earnings for this group of workers equal to its value added (i.e., its marginal revenue product). 
Conversely, some categories of employees may actually receive earnings in excess of their marginal revenue products and may therefore be defined as exploiters in that they benefit by obtaining some of the excess surplus that is generated by the exploitation of others.

In adopting this approach, we need not make any assumptions about which groups of employees may be overpaid. Our analysis can empirically identify which groups (if any) may receive some of the surplus generated by the exploitation of some types of workers. This approach contrasts with the Marxist view that begins with the theoretical assumption that only capitalists benefit from exploitation and that no groups of employees can ever be exploitative (Wright 2000).

\section{Exploitation and Rising Inequality in the Labor Market}

Wage and earnings inequalities have been notably increasing in recent decades, leading to a "polarization of the labor market" (Autor, Katz, and Kearney 2006:189). In this era of expanding inequality in the labor market, a measure of exploitation should not rule out the possibility that some groups of employees may be overpaid, thus benefitting from the exploitation of other groups of workers. Spiraling income increases for privileged employees with greater bargaining power may be depleting revenues for less advantaged workers.

Inequality associated with profits is severe (Liu, Sakamoto, and Su Forthcoming), but the existence of capital incomes should not lead us to dismiss the potential for exploitation that is associated with earnings. Although the share of the national income that is represented by wages and salaries has declined slightly in recent years, most of the gross domestic product still consists of employee compensation (Dietzenbacker, Lahr, and Los 2004). Even among the wealthiest 1 percent of households in 1998, wages and salaries represent the single largest component of their incomes (Piketty and Saez 2003:16).

\section{The Broader Theoretical Context}

Sociologists have not investigated exploitation in regard to earnings inequality in part because this issue is not an obvious topic in classical theory. Weber never developed a concept of exploitation nor is it inherent in Durkheim's functionalist view of stratification. Although exploitation is a central theme in Marxist theory, it does not consider exploitation in the distribution of labor earnings (Sakamoto and Liu 2006). Marxist theory instead focuses on capital income and profits because exploitation is defined to occur between the major classes (i.e., not within them).

In studying exploitation as the underpayment of earnings relative to the market value of the productivity of a given group of workers, our investigation is more consistent with Weber's view of class as "market situation" that affects one's access to scarce societal resources and "life chances." We analyze how exploitation results in the underpayment of earnings, which reduces the "life chances" of a given group of workers, and how the degree of the underpayment is typically influenced by their "market situation." 
Although aspects of Weber's views on social stratification may be broadly compatible with micro-economics, Weber's understanding of class as "market situation" envisions an economy that greatly differs from the characterization of "perfect competition" as commonly assumed by economists. Weber ([1922] 1978:342) acknowledges that "market situation" typically includes aspects of market closure, which "is directed against competitors who share some positive or negative characteristics; its purpose is always the closure of social and economic opportunities to outsiders" and "curbing competition." His approach analyzes how institutions promote the interests of various classes and social groups in their efforts to improve their employment circumstances by fostering market closure of various sorts (Murphy 1988). Market closure is most commonly thought of as being associated with monopolistic sellers, but other possible sources may include taxes, price controls and supports, cartels, labor unions, occupational certification practices, licensing, various imperfections of knowledge surrounding consumption and production, product differentiation, economies of scale, and patents (Sørensen 2000).

Weber's perspective on social stratification permits the differentiation of groups of workers who have varying degrees of power in their "market situation" to extract higher wages (Weber [1922] 1978:341-43). In contrast to the Marxist model of the struggle between two oppositional classes, Weber's concept of class as "market situation" is compatible with the idea that exploitative economic relations can be generated by processes relating to market closure affecting economic actors in the same class category. Our investigation of exploitation is consistent with Weber's general perspective on social stratification.

More recently, Sørensen's (2000) view of exploitation also recognizes the importance of market closure, which is included in his broader concept of rent. Our approach differs from his formulation, however, because Sørensen (2000:1536) proposes to define exploitation as being relative to the earnings that would be obtained in a perfectly competitive economy. By contrast, we measure exploitation as the difference between observed earnings and productivity as actually valued in the existing market. Because a perfectly competitive economy does not really exist in any known society, operationalizing Sørensen's view would be highly ambiguous if not untenable (Goldthorpe 2000; Wright 2000).

In sum, our foregoing methodology to measure exploitation provides intrinsically important information about economic underpayment as an ongoing process reflecting observed differentials between earnings and productivities as they are currently evaluated in the market economy. Although more conceptually concordant with the sociology of Weber, our approach is nonetheless consistent with the esprit of Marx's theory because exploitation is viewed as being inherently linked to the actual labor process, which creates value that is partially appropriated as that process of antagonistic relations unfolds; or as stated by Wright (2000:1565), "exploitation depends upon the appropriation of labor effort." Our measure of exploitation provides inherently meaningful information about the extent to which the labor process results in the appropriation of value that is directly indicative of the augmentation of actual inequalities, which again fulfills the intent of the Marxist vision. 


\section{TOWARDS A THEORY OF THE SOURCES OF EXPLOITATION}

Our investigation is inherently preliminary in nature. We therefore do not advocate a particular coherent theory of the sources of exploitation. We instead develop a methodology that future researchers may utilize so as to advance cumulative knowledge about the various determinants of exploitation. In this context, we identify several relevant variables that prior literature suggests should be investigated as potentially significant factors.

One often cited factor is occupational structure (Grusky 2005). Even Marxist formulations that seek to differentiate themselves from the Weberian perspective nonetheless utilize occupational categories as key concepts in their theoretical framework albeit in terms of a more esoteric nomenclature (Wright 2000). As discussed by Grusky (2005:61), "occupational groupings have emerged as the elementary building blocks of modern and postmodern labor markets." Furthermore, "the working institutions of closure are organized largely at the occupational level and the potential for rent therefore emerges at that level" (Grusky 2005:74).

Demographic and ascribed sources of inequality have also been studied by sociologists. These patterns of wage differentials often stem from various discriminatory practices towards women and racial/ethnic minorities. In terms of the Weberian approach, some of these practices serve to weaken the "market situation" of women and racial/ethnic minorities. As noted by Weber ([1922] 1978:342), "one group of competitors takes some externally identifiable characteristic of another group of (actual or potential) competitors - race, language, religion, local or social origin, descent, residence, etc.- - as a pretext for attempting their exclusion."

In regard to the wage penalty for women, prior research has emphasized the significance of gender segregation into lower level jobs (Jacobs 2001). This segregation is often exacerbated by reduced chances for upward mobility and promotions within firms (Petersen and Morgan 1995). Gender segregation may lead to comparative worth processes that tend to "de-value" jobs that are labeled as "women's work," thus leading to the underpayment of those jobs relative to their actual productivities (England, Thompson, and Aman 2001). The labor market competitiveness of women may be further disadvantaged by family relations (Marini and Fan 1997) including household migration patterns (McKinnish 2008) and motherhood (Budig and England 2001; Correll, Benard, and Paik 2007).

In terms of race and ethnicity, labor market discrimination against African Americans has been documented. Discriminatory attitudes and queuing processes result in hiring disadvantages (Bertrand and Mullainathan 2004; Kaufman 2001). Human capital development and career mobility are often hampered (Tomaskovic-Devey, Thomas, and Johnson 2005). Labor market segmentation and racial segregation in employment may further reduce the returns to human capital for African Americans (Kaufman 2001). Pre-labor market discrimination particularly in regard to residential segregation, educational opportunity, and lower socioeconomic background represent additional disadvantages (Massey and Denton 1993). Though on a somewhat lesser scale, similar labor market processes may operate for Hispanics (Kaufman 2001).

In regard to educational attainment, prior research indicates that manufacturing firms with more highly educated employees tend to have greater productivity net 
of other variables (Hellerstein, Neumark, and Troske 1999:428). This result is consistent with either the human capital or the market-signaling explanations of the effect of education (Hellerstein et al. 1999:433). For our purposes, either explanation (or some combination of the two) justifies the inclusion of education into our models because one's "market situation" is clearly enhanced whether schooling improves one's productivity or whether it signals to prospective employers that one is a more trainable worker.

Marital status is another labor market factor that may be significant because married persons may have greater preferences for higher earnings and at least married men tend to have higher earnings as well (Croson and Gneezy 2009; Hellerstein et al. 1999; Johnson 2005). In addition to higher earnings, married persons in the manufacturing sector also seem to have slightly greater productivity (Hellerstein et al. 1999). Age is another demographic factor that is often correlated with the development of work skills as well as position in career hierarchies (Sørensen 1977). A quadratic specification for age is typically used.

The aforementioned studies indicate that these traditional sources of inequalityincluding occupation, gender, race, ethnicity, education, marital status, and agemay be associated with exploitation by lowering earnings in the labor market. Although prior research on these variables is voluminous, most previous studies typically assume that the lower earnings associated with these variables do not simply derive from lower levels of productivity. In the following, we are able to assess this assumption more explicitly by estimating a model that uses information on both productivity and earnings differentials.

\section{METHODOLOGY}

\section{Data}

We limit this investigation to the manufacturing sector because it is generally viewed as having more valid productivity data (Kim and Sakamoto 2008b). Another rationale for this restriction is simply data availability since productivity statistics for other sectors have not been collected until very recently. Due to this restriction, our results obviously cannot be generalized beyond the manufacturing sector.

Our key data source that provides annual information on productivity and other related factors for manufacturing industries is the Manufacturing Industry Database (NBER-CES MID), which is compiled by the National Bureau of Economic Research and the Center for Economic Studies of the U.S. Census Bureau. These data are obtained from various official sources, most notably the Annual Survey of Manufactures and the Census of Manufactures. This database extends through 1996 and our analysis thus ends with that year.

However, this database does not provide any information on workers' characteristics in each manufacturing industry. We therefore use the NBER-CES MID in conjunction with other annual data from the Current Population Survey (CPS). We investigate the CPS beginning with 1971 because of its consistent use of occupational and industrial codes that are based on the 1970 Census Bureau classification. Workers' characteristics are summarized in terms of the proportions observed for various demographic and socioeconomic categories (i.e., gender, race, 
occupational category, educational level, etc.) in each manufacturing industry for each year.

We matched the NBER-CES MID data on productivity (and other related factors) and the CPS data on workers' characteristics on the basis of three-digit Standard Industrial Classification (SIC) codes. That is, our unit of analysis is the three-digit SIC code. At this aggregate level, productivity (i.e., the dollar value of the total output of a manufacturing industry during a given year) and workers' characteristics (i.e., the proportions observed on various variables for the workers in a manufacturing industry during a given year) are linked for each three-digit SIC code in each year. We thereby obtained a balanced panel data set that includes 1,456 cases consisting of 56 manufacturing industries observed annually from 1971 to 1996.

\section{Statistical Models}

Using the aggregate data set described above, two regression equations are estimated in which the unit of analysis is the three-digit SIC code whose scores on the variables vary annually over time. The dependent variable for the first regression is productivity, and the independent variables include the proportions indicating the various characteristics of workers in that industry during a given year. The second regression equation is also estimated using this data set, but in this case the dependent variable is the total earnings paid to all workers in the particular industry during a given year. The independent variables for the second regression include the exact same worker characteristics that were used as independent variables in the first regression.

Using this model, exploitation can be ascertained as occurring to those groups of workers for whom their incremental contribution to total productivity is less than their incremental association with total earnings. Workers are being underpaid relative to their value when their earnings do not reflect the increase in total productivity that results from their employment. They are exploited because they are not receiving the full economic value of their work.

The first regression of total productivity is the production function. Following standard practice, this regression is specified as a Cobb-Douglas model:

$$
V_{i t}=A K_{i t}^{\alpha} L_{i t}^{\beta}
$$

where $A$ is a constant reflecting the scaling of the measures and $V_{i t}$ is productivity at time $t$ in industry $i$. Productivity here refers to the value added or the market value of the output produced minus energy and material costs. $K_{i t}$ refers to the total value of the real capital stock that is used in production at time $t$ in industry $i$. $L_{i t}$ refers to the total number of workers employed at time $t$ by industry $i$.

The Cobb-Douglas production function is widely used because it has generally been confirmed in prior studies that the relationship between total output and total input typically involves interaction effects between the various factors of production. This latter property is built into the Cobb-Douglas specification due to its multiplicative formulation (Stolzenberg and Land 1983). The coefficients of this model may be interpreted as elasticities, which refer to "the proportional change 
in $Y$ [i.e., the dependent variable] per proportionate change in $X$ [i.e., a given independent variable]" (Stolzenberg and Land 1983:652).

To investigate the effects of workers' characteristics on productivity, we substitute $L_{i t}$ for $Q_{i t}$, which refers to the various variables computed for the workers in each industry. To illustrate this method, suppose that the workforce characteristic being considered is gender composition. Dropping the time and industry subscripts for simplicity, $Q_{i t}$ can then be expressed by equation 2 :

$$
Q=L\left[1+\left(\delta_{1}-1\right) L_{F} / L\right]=L\left[1+\left(\delta_{1}-1\right) F\right]
$$

where $L$ refers to the total number of workers in an industry and $L_{F}$ refers to the number of female workers. $F$ denotes the proportion of female workers among all workers. $\delta_{1}$ refers to the relative marginal productivity associated with employing female workers (as compared to employing male workers). For example, when $\delta_{1}$ is equal to unity, then $L\left[1+\left(\delta_{1}-1\right) F\right]$ becomes $L$ because $(1-1) F$ reduces to zero. This result would indicate that employing more female workers is associated with the same increase in productivity as employing more male workers.

The actual labor input specification that we use is:

$$
\begin{aligned}
Q= & L \times\left[1+\left(\delta_{1}-1\right) F\right] \times\left[1+\left(\delta_{2}-1\right) M\right] \times\left[1+\left(\delta_{3}-1\right) A_{m}+\left(\delta_{4}-1\right) A_{0}\right] \\
& \times\left[1+\left(\delta_{5}-1\right) R_{1}+\left(\delta_{6}-1\right) R_{2}+\left(\delta_{7}-1\right) R_{3}\right] \times\left[1+\left(\delta_{8}-1\right) E\right] \\
& \times\left[1+\left(\delta_{9}-1\right) O_{1}+\left(\delta_{10}-1\right) O_{2}+\left(\delta_{11}-1\right) O_{3}+\left(\delta_{12}-1\right) O_{4}+\left(\delta_{13}-1\right) O_{5}\right]
\end{aligned}
$$

where $F$ denotes the percent female, $M$ denotes the percent married, $A_{m}$ refers to the percent of employees who are middle-aged (i.e., thirty-five to fifty four years old), and $A_{o}$ refers to the percent of employees who are older (i.e., fifty-five or more years of age). For these age groups, the reference category is young workers aged eighteen to thirty-four. $R_{1}$ to $R_{3}$ denote the percents in different mutually exclusive racial/ethnic groups (i.e., non-Hispanic African Americans, Hispanics, and other non-Hispanic nonwhites) with non-Hispanic whites being the reference category. $E$ refers to the percent of employees who have a college degree or some higher degree. $O_{1}$ to $O_{5}$ refer to the percents in different occupational categories, including professionals, managers, technicians (e.g., draftsmen, pilots, medical technicians, dental assistants, etc.), blue-collar workers (including craft workers, operatives, and laborers), and sales or service workers. The reference group for the occupational categories is other white-collar workers (including administrative support occupations such as secretaries). These variables for the labor input function follow from our earlier discussion regarding the sources of inequality and market closure.

After inserting $Q$ (as given by equation 3 ) for $L$ in equation 1, we take the log on both sides of the resulting equation to transform it into its additive form:

$$
\begin{aligned}
\ln (V)= & c+\alpha \ln (K)+\beta\left\{\ln (\mathrm{L})+\ln \left[1+\left(\delta_{1}-1\right) F\right]+\ln \left[1+\left(\delta_{2}-1\right) M\right]\right. \\
& +\ln \left[1+\left(\delta_{3}-1\right) A_{m}+\left(\delta_{4}-1\right) A_{0}\right]+\ln \left[1+\left(\delta_{5}-1\right) R_{1}+\left(\delta_{6}-1\right) R_{2}\right. \\
& \left.+\left(\delta_{7}-1\right) R_{3}\right]+\ln \left[1+\left(\delta_{8}-1\right) E_{3}\right]+\ln \left[1+\left(\delta_{9}-1\right) O_{1}+\left(\delta_{10}-1\right) O_{2}\right. \\
& \left.\left.+\left(\delta_{11}-1\right) O_{3}+\left(\delta_{12}-1\right) O_{4}+\left(\delta_{13}-1\right) O_{5}\right]\right\}+I_{i}+T+I N D T_{i}+e
\end{aligned}
$$


where $e$ refers to the residual error and $\alpha$ refers to the expected percent increase in value added by a 1 percent increase in capital (i.e., $\alpha$ is an elasticity) holding labor input constant. $\beta$ denotes the expected percent increase in valued added by a 1 percent increase in labor input holding capital constant. Following up on our discussion above, the $\delta_{j}$ in equation 4 refers to the differential marginal productivity between the reference group and the $j$ th group. When $\delta_{j}$ is equal to unity for the $j$ th group, then its productivity is equal to that of the reference group. Conversely, when $\delta_{\mathrm{j}}$ is less than unity for the $j$ th group, then its productivity is less than that of the reference group while a $\delta$ greater than unity indicates that the productivity of the $j$ th group is greater than the reference group.

Even after taking the $\log$ on both sides, equation 4 cannot be estimated with ordinary least squares (OLS) because the components of labor input (e.g., $\ln [1+$ $\left.\left.\left(\delta_{1}-1\right) F\right]\right)$ are not linearly related. The total error associated with the estimation of the regression model cannot be directly minimized using the standard OLS solutions. We therefore estimate equation 4 using a nonlinear least squares method.

Equation 4 includes dummy variables to control for industry (i.e., $I_{i}$ ), an intervallevel variable to control for time (i.e., $T$ ) in terms of an annual increment, and interactions between industry and time (i.e., $I N D T_{i}$ ). By adding the industry dummy variables, we control for industry-specific fixed-effects in the production function. Our estimates are free from cross-sectional heterogeneity between industries. The estimated parameters indicate net changes in productivity within industries according to their changes in capital and labor-input over time. The time variable (which is centered at 1971) controls for annual technological and other period changes during these years while the interaction terms between industry and time control for the heterogeneity in these changes across the industries.

The other regression in our statistical model is an earnings function, which refers to the total annual earnings paid to all employees in a given industry during a particular year. The covariates for the earnings function are the same as those for the production function. The variables to control for the industry-specific fixed effects, year, and the interactions between industry and time are also included. They control for other changes in the "market situation" of industries such as declining unionization, increasing global competition, and altering legal regulations over this time period (Kim and Sakamoto 2008c). Although capital is usually thought of as being an independent variable in a production function, capital is included in the earnings function because prior research suggests that workers in industries with greater capital investment receive slightly higher wages (Dickens and Katz 1987). Our earnings function is thus specified as:

$$
\begin{aligned}
\ln (E)= & c+\alpha \ln (K)+\beta\left\{\ln (\mathrm{L})+\ln \left[1+\left(\zeta_{1}-1\right) F\right]+\ln \left[1+\left(\zeta_{2}-1\right) M\right]\right. \\
& +\ln \left[1+\left(\zeta_{3}-1\right) A_{m}+\left(\zeta_{4}-1\right) A_{\mathrm{o}}\right]+\ln \left[1+\left(\zeta_{5}-1\right) R_{1}+\left(\zeta_{6}-1\right) R_{2}\right. \\
& \left.+\left(\zeta_{7}-1\right) R_{3}\right]+\ln \left[1+\left(\zeta_{8}-1\right) E_{1}\right]+\ln \left[1+\left(\zeta_{9}-1\right) O_{1}+\left(\zeta_{10}-1\right) O_{2}\right. \\
& \left.\left.+\left(\zeta_{11}-1\right) O_{3}+\left(\zeta_{12}-1\right) O_{4}+\left(\zeta_{13}-1\right) O_{5}\right]\right\}+I_{i}+T+I N D T_{i}+e
\end{aligned}
$$

where $\ln (E)$ refers to log total annual earnings paid to all employees in a particular industry during a given year. The $\zeta$ 's in equation 5 represent the relative marginal 
earnings in comparison to the relevant reference group after controlling for the other variables in the equation. If all of these groups of workers are paid equally (net of the other covariates in the model), then all of the $\zeta^{\prime}$ s will be equal to unity. Deviations from unity indicate earnings differentials.

\section{Estimating the Level of Exploitation for Particular Groups of Workers}

As explained above, when a particular group has a higher relative marginal productivity compared to the reference group (on average), then its $\delta$ will be greater than one, while in the opposite case, it will be less than one. When a particular group has higher earnings compared to the reference group (on average), then its $\zeta$ will be greater than one, while in the opposite case, it will be less than one. When workers of a particular category are paid exactly according to their marginal productivities (on average), then there should be no difference between $\delta$ and $\zeta$ for that group.

To assess whether a particular group of workers is exploited, we test whether it is underpaid in that its marginal contribution to productivity (i.e., $\delta$ ) is greater than its earnings differential (i.e., $\zeta$ ). If the $\delta$ for a given group of workers is greater than its $\zeta$, then we conclude that this group is exploited by the degree of the difference. The statistical significance of the estimated difference may be assessed using a Wald test that follows a chi-square sampling distribution with 1 degree of freedom according to the null hypothesis of equality between $\delta$ and $\zeta$.

When the marginal productivity of a particular group of workers is less than its earnings, then its $\delta$ will be less than its corresponding $\zeta^{\prime}$. In this case, the given group of workers is benefiting from the exploitation of other groups of workers or is obtaining rewards that the other groups of workers may not be receiving. In either case, we refer to this given group of workers as being exploiters because they extract from the market more than their marginal productivity.

Our methodology estimates group-level differentials on average as evidenced in variation across industries. Our results therefore do not identify any individual-level relationships. In reality, our findings may perhaps sometimes be indicative of similar individual-level relationships, but extrapolating to the individual-level should be recognized as an interpretation imputed by a researcher (presumably on the basis of other information from other studies that do use individual-level data).

\section{Investigating Exploitation by Relative Position in the Distribution of Earnings}

We next estimate the following production function in order to investigate exploitation by relative position in the distribution of earnings:

$$
\begin{aligned}
\ln (V)= & c+\alpha \ln (K)+\beta\left\{\ln (\mathrm{L})+\ln \left[1+\left(\delta_{14}-1\right) Q_{1}+\left(\delta_{15}-1\right) Q_{2}\right.\right. \\
& \left.\left.+\left(\delta_{16}-1\right) Q_{4}+\left(\delta_{17}-1\right) Q_{5}\right]\right\}+I_{i}+T+I N D T_{i}+e
\end{aligned}
$$

where $Q_{1}$ refers to the percent of workers in the given industry during a particular year that are being paid in the first quintile of earnings (from the lowest value to the 20th percentile), where the latter cutoff is determined on the basis of the 
distribution of earnings for the entire manufacturing sector during that year. Similarly, $Q_{2}$ refers to the second quintile (from the 20th percentile to the 40th percentile for the manufacturing sector in a given year), $Q_{4}$ refers to the fourth quintile (from the 60th percentile to the 80th percentile for the manufacturing sector in a given year), and $Q_{5}$ refers to the highest quintile (greater than the 80th percentile for the manufacturing sector in a given year). Workers in the higher quintiles have a higher relative position in the distribution of earnings in a given year.

Because the cutoffs for the quintiles are based on the distribution of earnings for the entire manufacturing sector during a particular year, the independent variables in equation 6 indicate how equal (or unequal) the distribution of earnings is for a given industry during that year as compared to the national average for this sector. If a given industry in a particular year had exactly the same level of earnings inequality as the manufacturing sector as a whole, then the values on its $Q^{\prime}$ s would be exactly 20 percent each. If a given industry in a particular year were more unequal than the national average, then more of its workers (i.e., greater than 20 percent) would be concentrated in the lower and higher quintiles.

In equation 6, the reference group is the third quintile (from the 40th percentile to the 60th percentile for the manufacturing sector in a given year). The $\delta^{\prime}$ s in this specification refer to the marginal productivity of workers in a particular earnings quintile relative to workers in the third earnings quintile. To the extent that workers in the fourth and fifth quintiles contribute more to productivity than do the workers in the third quintile, then the $\delta^{\prime}$ s should be greater than unity for the fourth and fifth quintiles.

The earnings function that is associated with equation 6 is:

$$
\begin{aligned}
\ln (E)= & c+\alpha \ln (K)+\beta\left\{\ln (\mathrm{L})+\ln \left[1+\left(\zeta_{14}-1\right) Q_{1}+\left(\zeta_{15}-1\right) Q_{2}\right.\right. \\
& \left.\left.+\left(\zeta_{16}-1\right) Q_{4}+\left(\zeta_{17}-1\right) Q_{5}\right]\right\}+e
\end{aligned}
$$

where the reference category is again the third quintile as determined by the 40th and 60th percentiles for the manufacturing sector in a given year. In this model, the $\zeta$ 's refer to the relative earnings differentials between workers in a particular quintile as compared to workers in the third quintile. To the extent that the relative earnings differential for workers in a particular quintile is matched by a corresponding increase in its relative marginal productivity, then $\delta$ should equal $\zeta$, which can be again assessed with a Wald chi-square test. To the extent that the workers in a particular quintile are overpaid relative to their marginal productivity, however, then their $\zeta$ would be greater than their $\delta$. The latter case may be interpreted as exploitative because a given quintile group extracts earnings that are higher than its marginal productivity.

The earnings function as shown by equation 7 does not include any of the variables for occupation, demography, capital investment, industry-specific fixed effects, or year. The rationale for these omissions is that equation 7 is not meant to be a causal model of how "market situation" affects earnings, but rather an equation that assesses an accounting relationship. The values of the $Q^{\prime}$ s represent the actual earnings outcomes of the bargaining process, so variables that predict the latter should not be included in the model. 
For a similar reason the production function as given by equation 6 does not include any variables for occupation and demographic characteristics. Workers identified by those variables may be located in different quintiles. The inclusion of variables to indicate occupation and demographic traits would have resulted in a specification in which the $\delta^{\prime}$ s do not refer to the total differentials in marginal productivity associated on average with the employees in a given quintile. Equation 6 does include, however, variables to indicate capital investment, industry-specific fixed effects, year, and their interactions. These latter variables are needed in order to control for differences in production functions across these industries and over this time period.

\section{EMPIRICAL RESULTS}

\section{Descriptive Statistics}

Table 1 shows the descriptive statistics. The data for value added, earnings, and capital investment are in terms of 1984 constant dollars. The mean of value added for these industries in the manufacturing sector increased substantially from $\$ 13,913$ million in 1971 to $\$ 19,913$ million in 1996, while the mean number of workers employed per industry actually declined slightly from 313,000 in 1971 to 309,000 in 1996 . These results suggest that manufacturing productivity per employee improved dramatically for this time period. However, mean earnings per employee increased only modestly from 1971 to 1996, as is evident in Table 1.

Table 1 shows that the proportion of female workers in the manufacturing sector increased during this time period. The share of Hispanics also grew substantially, while the share of non-Hispanic whites declined. The share of non-Hispanic others increased (largely reflecting the influx of Asians), while the share of non-Hispanic African Americans declined very slightly. Regarding educational composition, the proportion of workers with a college degree or higher educational attainment more than doubled from .085 in 1971 to .180 in 1996. The proportion of managerial workers grew substantially over this period from .059 to .101, while the share of blue-collar workers decreased from .685 to .628 .

\section{Productivity, Earnings, and Exploitation among Workers in the Manufacturing Sector}

Table 2 shows the estimates for our multivariate models (i.e., equations 4 and 5) investigating the effects of demographic and occupational variables. As expected on the basis of prior research, both capital investment and labor input are clearly positive factors of production. A 1 percent increase of capital is predicted to raise value added by .05 percent (i.e., the estimate of $\alpha$ ), which is net of the other covariates in the model. Net of capital, a 1 percent increase in labor input (holding constant the mix of worker categories and types) is expected to increase value added by .96 percent (i.e., the estimate of $\beta$ ). Both of these net effects are statistically significant at any conventional level.

The estimates of the occupational and demographic variables show some variation in Table 2. In the productivity equation, the coefficient for female workers is .85, 


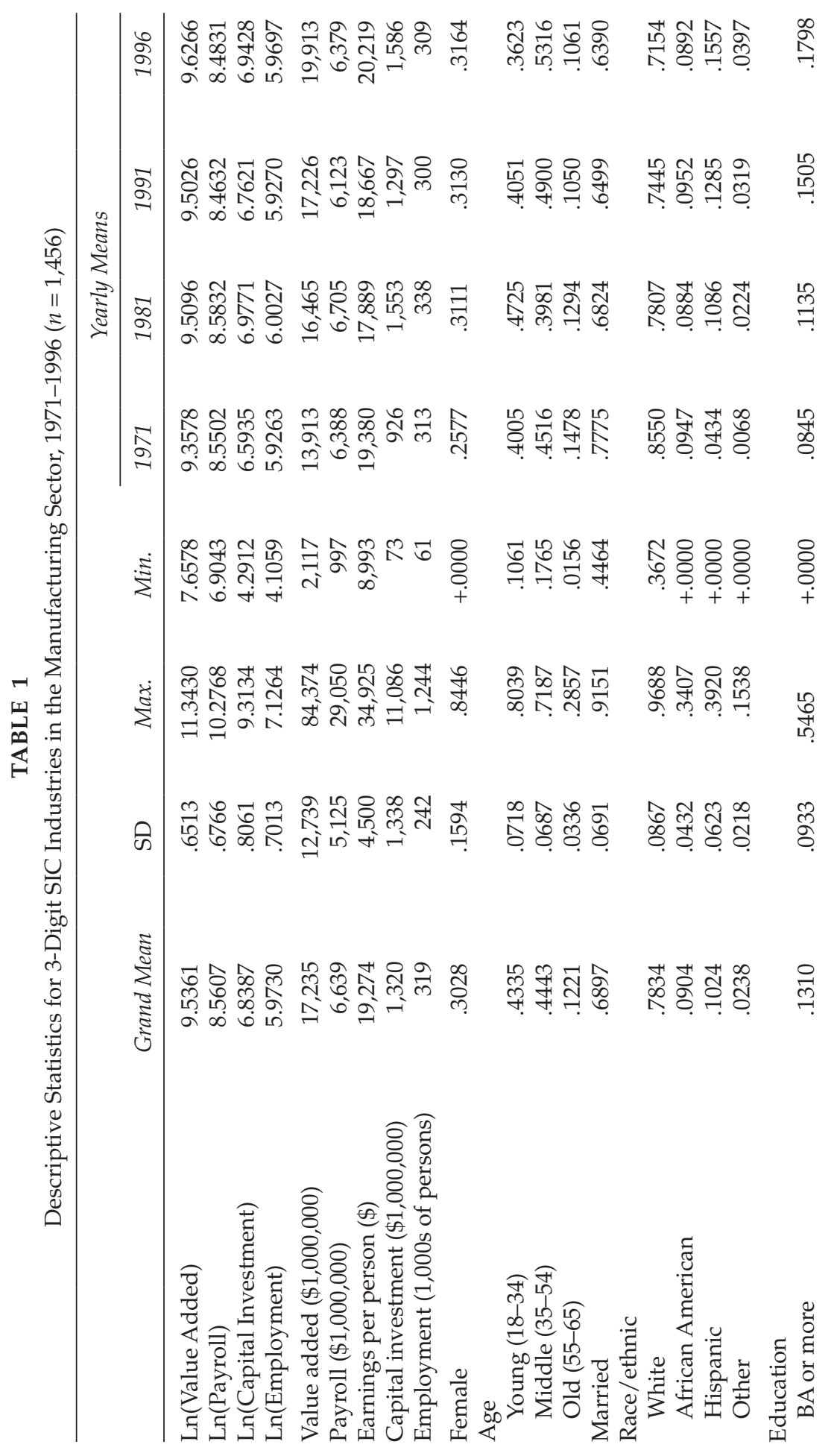




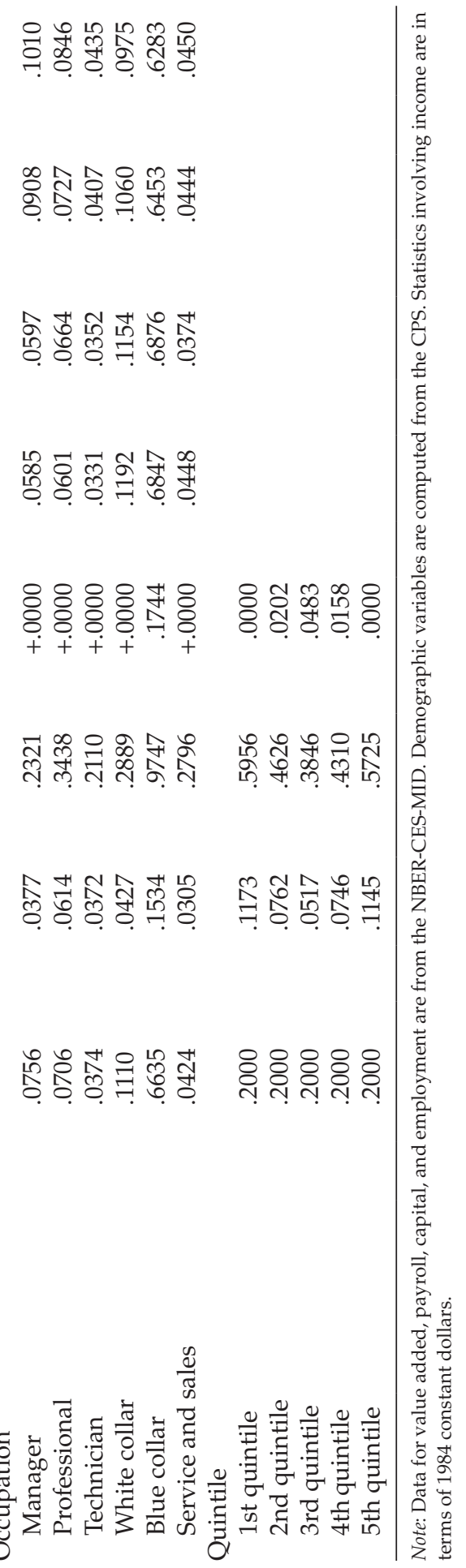


TABLE 2

Nonlinear Least Squares Estimates of Productivity and Earnings Model

\begin{tabular}{|c|c|c|c|c|c|c|}
\hline & $\begin{array}{c}\text { Value Added } \\
\text { (1) } \\
\text { Coeffi. (SE) }\end{array}$ & Sig. & $\begin{array}{l}\text { Earnings } \\
\quad(2) \\
\text { Coeffi. (SE) }\end{array}$ & Sig. & $\begin{array}{l}\text { Wald Test } \\
(2)-(1) \\
\text { Coeffi. }\left[\chi^{2}\right]\end{array}$ & Sig. \\
\hline$c$ & $\begin{array}{l}3.4498 \\
(.2022)\end{array}$ & $* * *$ & $\begin{array}{l}9.4512 \\
(.1166)\end{array}$ & $* * *$ & & \\
\hline$\alpha$ & $\begin{array}{c}.0512 \\
(.0125)\end{array}$ & $* * *$ & $\begin{array}{l}.0615 \\
(.0074)\end{array}$ & $* * *$ & & \\
\hline$\beta$ & $\begin{array}{l}.9610 \\
(.0334)\end{array}$ & $* * *$ & $\begin{array}{c}.9858 \\
(.0105)\end{array}$ & $* * *$ & & \\
\hline Female & $\begin{array}{c}.8549 \\
(.0622)\end{array}$ & * & $\begin{array}{l}.4676 \\
(.0315)\end{array}$ & $* * *$ & $\begin{array}{c}-.3873 \\
{[30.84]}\end{array}$ & $* * *$ \\
\hline \multicolumn{7}{|l|}{ Age $^{a}$} \\
\hline Middle & $\begin{array}{l}1.0721 \\
(.0569)\end{array}$ & & $\begin{array}{l}1.4667 \\
(.0630)\end{array}$ & $* * *$ & $\begin{array}{c}.3946 \\
{[21.58]}\end{array}$ & $* * *$ \\
\hline Old & $\begin{array}{l}.9135 \\
(.0955)\end{array}$ & & $\begin{array}{l}1.3845 \\
(.0946)\end{array}$ & $* * *$ & $\begin{array}{r}.4710 \\
{[12.29]}\end{array}$ & $* * *$ \\
\hline Married & $\begin{array}{l}1.0082 \\
(.0676)\end{array}$ & & $\begin{array}{l}1.1324 \\
(.0586)\end{array}$ & * & $\begin{array}{c}.1242 \\
{[1.93]}\end{array}$ & \\
\hline \multicolumn{7}{|l|}{ Race $^{\mathrm{b}}$} \\
\hline African American & $\begin{array}{l}1.2181 \\
(.1033)\end{array}$ & * & $\begin{array}{c}.9883 \\
(.0701)\end{array}$ & & $\begin{array}{l}-.2298 \\
{[3.39]}\end{array}$ & \\
\hline Hispanic & $\begin{array}{l}.9864 \\
(.0846)\end{array}$ & & $\begin{array}{c}.7007 \\
(.0563)\end{array}$ & $* * *$ & $\begin{array}{l}-.2857 \\
{[7.91]}\end{array}$ & $* *$ \\
\hline Other & $\begin{array}{l}1.0974 \\
(.1866)\end{array}$ & & $\begin{array}{l}1.0037 \\
(.1295)\end{array}$ & & $\begin{array}{l}-.0937 \\
{[0.17]}\end{array}$ & \\
\hline College or more education & $\begin{array}{l}1.1901 \\
(.0790)\end{array}$ & $*$ & $\begin{array}{l}1.2684 \\
(.0608)\end{array}$ & $* * *$ & $\begin{array}{c}.0783 \\
{[0.62]}\end{array}$ & \\
\hline \multicolumn{7}{|l|}{ Occupation $^{c}$} \\
\hline Managers & $\begin{array}{l}1.1228 \\
(.1823)\end{array}$ & & $\begin{array}{l}1.7777 \\
(.1516)\end{array}$ & $* * *$ & $\begin{array}{c}.6549 \\
{[7.63]}\end{array}$ & $* *$ \\
\hline Professionals & $\begin{array}{l}1.1537 \\
(.1818)\end{array}$ & & $\begin{array}{l}1.3044 \\
(.1262)\end{array}$ & * & $\begin{array}{c}.1507 \\
{[0.46]}\end{array}$ & \\
\hline Technicians & $\begin{array}{l}.9320 \\
(.2103)\end{array}$ & & $\begin{array}{l}1.1148 \\
(.1442)\end{array}$ & & $\begin{array}{c}.1828 \\
{[0.51]}\end{array}$ & \\
\hline Blue collar & $\begin{array}{l}1.1911 \\
(.1381)\end{array}$ & & $\begin{array}{c}.8142 \\
(.0627)\end{array}$ & $* *$ & $\begin{array}{l}-.3770 \\
{[6.18]}\end{array}$ & * \\
\hline Service and sales & $\begin{array}{c}0.9308 \\
(0.1925)\end{array}$ & & $\begin{array}{c}.9957 \\
(.1257)\end{array}$ & & $\begin{array}{c}.0649 \\
{[0.08]}\end{array}$ & \\
\hline Adjusted $R^{2}$ & .9891 & & .9946 & & & \\
\hline Industry dummies & Yes & & Yes & & & \\
\hline Time variable & Yes & & Yes & & & \\
\hline Industry $\times$ Time interactions & Yes & & Yes & & & \\
\hline
\end{tabular}

Note: Numbers within round brackets are standard errors and numbers within square brackets are chi-squares.

a'Young: aged 18-34; middle: aged 35-54; old: aged 55-65.

${ }^{b}$ Reference group is white.

cReference group is other white-collar workers.

${ }^{*} p<.05 ;{ }^{* *} p<.01 ;{ }^{* * *} p<.001$ (two-tailed tests). 
indicating that industries that employ more female workers have 15 percent less productivity than industries employing more male workers. In other words, the marginal productivity associated with employing women in these results is 15 percent less than that for men at least at the industrial level. ${ }^{1}$ The other coefficients that are statistically significant at the .05 level in the productivity equation include African American and college education attainment. ${ }^{2}$ The estimate for African Americans is 1.22, indicating that employing black workers results in 22 percent higher industrial productivity than employing white workers. The coefficient for educational attainment indicates that employing workers who have a college degree is associated with 19 percent higher industrial productivity than workers without a college degree.

None of the occupational variables are statistically significant at the .05 level in the productivity function for Table 2 . These results do not provide strong evidence that the marginal productivity of any of these occupational categories exceeds that of the omitted category, which is other white-collar workers (at least for industriallevel data for the manufacturing sector), net of education and demographic variables. These findings may perhaps derive from a substantial degree of heterogeneity within these broad occupational categories.

Several of the occupational variables are statistically significant, however, in the earnings equation in Table 2. Relative to other white-collar workers and net of the other variables in the model, the employment of managers is associated with about 78 percent higher earnings paid at the industrial level, while the employment of professionals is associated with about 30 percent higher earnings paid at the industrial level. On the other hand, the employment of blue-collar workers is associated with about 19 percent (i.e., 1.0 - .81) lower earnings paid at the industrial level than is the employment of other white-collar workers.

As for the demographic variables in the earnings equation in Table 2, the results indicate the following in regard to total earnings paid at the industrial level (net of the other variables in the model): 47 percent more for the employment of middleaged workers (compared to younger workers), 38 percent more for the employment of older workers (compared to younger workers), 13 percent more for the employment of married workers (compared to unmarried workers), 30 percent less for the employment of Hispanic workers (compared to white workers), and 53 percent less for the employment of female workers (compared to male workers). ${ }^{3}$

As was discussed earlier, we measure exploitation as the difference between productivity and earnings differentials for a particular group. For female workers, Table 2 shows that the Wald chi-square test statistic (i.e., 30.84) for their underpayment is statistically significant at any conventional level. Although employing women is associated with 85 percent of the industrial productivity of employing men, women only earn 47 percent of what men earn. Thus, female workers are underpaid (i.e., exploited) by about 39 percent (i.e., 85.5 percent -46.8 percent), as shown in the last column of Table 2. Net of the other factors controlled for in the model using industrial data, the productivity of female workers is underpaid by 39 percent compared to the extent to which the productivity of male workers is paid.

Another exploited group is Hispanics. In Table 2, their $\delta$ is estimated to be .99 , while their $\zeta$ is estimated to be .70 . The difference implies that Hispanics are 
underpaid by 29 percent. Given a Wald chi-square test statistic of 7.91, this underpayment at the industrial level is statistically significant at the .005 level.

The Wald chi-square test statistic is also significant for blue-collar workers. Although their estimated $\delta$ of 1.19 implies that they are associated with 19 percent more industrial productivity than other white-collar workers, the estimated $\zeta$ of .81 implies that blue-collar workers earn 19 percent less than other white-collar workers. These two estimates together imply that blue-collar workers are underpaid by about 38 percent.

The Wald chi-square test statistic for the estimated difference between $\delta$ and $\zeta$ for African Americans is 3.39, as shown in Table 2. This difference is not statistically significant at the .05 level, which has a critical value of 3.84. However, other research discussed above suggests that African Americans face discrimination in the labor force, and a chi-square test statistic of 3.39 implies a relatively close $p$ value of .0656 . We are therefore inclined to reject the null hypothesis that $\delta$ and $\zeta$ are equal for African Americans. Given that conclusion, the estimated underpayment for African Americans is 23 percent.

Other results in Table 2 indicate that several groups are exploiters. For middleaged workers and for older workers, the estimated $\delta$ is less than the estimated $\zeta$, and these differences are statistically significant at any conventional level. In the case of middle-aged workers (i.e., thirty-five to fifty-four years of age) the overpayment amounts to 40 percent while for older workers (i.e., fifty-five or more years of age) the overpayment amounts to 47 percent. The other group of exploiters is the managerial occupation. They have the highest level of overpayment, which amounts to 66 percent.

These estimates of differentials in productivity, earnings, and exploitation refer to proportionality contrasts relative to a particular reference category. We have not provided any specific estimates of the levels of productivity, earnings, and exploitation for the reference groups per se because these quantities are not identified in these models. Our results about the levels of exploitation are relative to a particular reference group and do not imply that that reference group itself is not exploited as well.

\section{Productivity, Earnings, and Exploitation by Relative Position in the Distribution of Earnings}

Table 3 shows the estimates of the functions for industrial productivity and earnings by relative position in the distribution of earnings. In order to investigate whether the level of exploitation has been increasing over this time period, the model is estimated twice. First, it is estimated using only the data for the earlier years (i.e., 1971 to 1982). Then it is estimated using only the data for the later years (i.e., 1983 to 1996).

We chose this cutoff for several reasons. First, it yields two periods with an approximately similar number of years, which yields greater statistical power. Second, in 1983 the CPS made a few slight changes to its industrial classification, making that year a natural cutoff point. Third, the early 1980s was the beginning of the rapid rise in wage and income inequalities as well as the start of the acceleration 


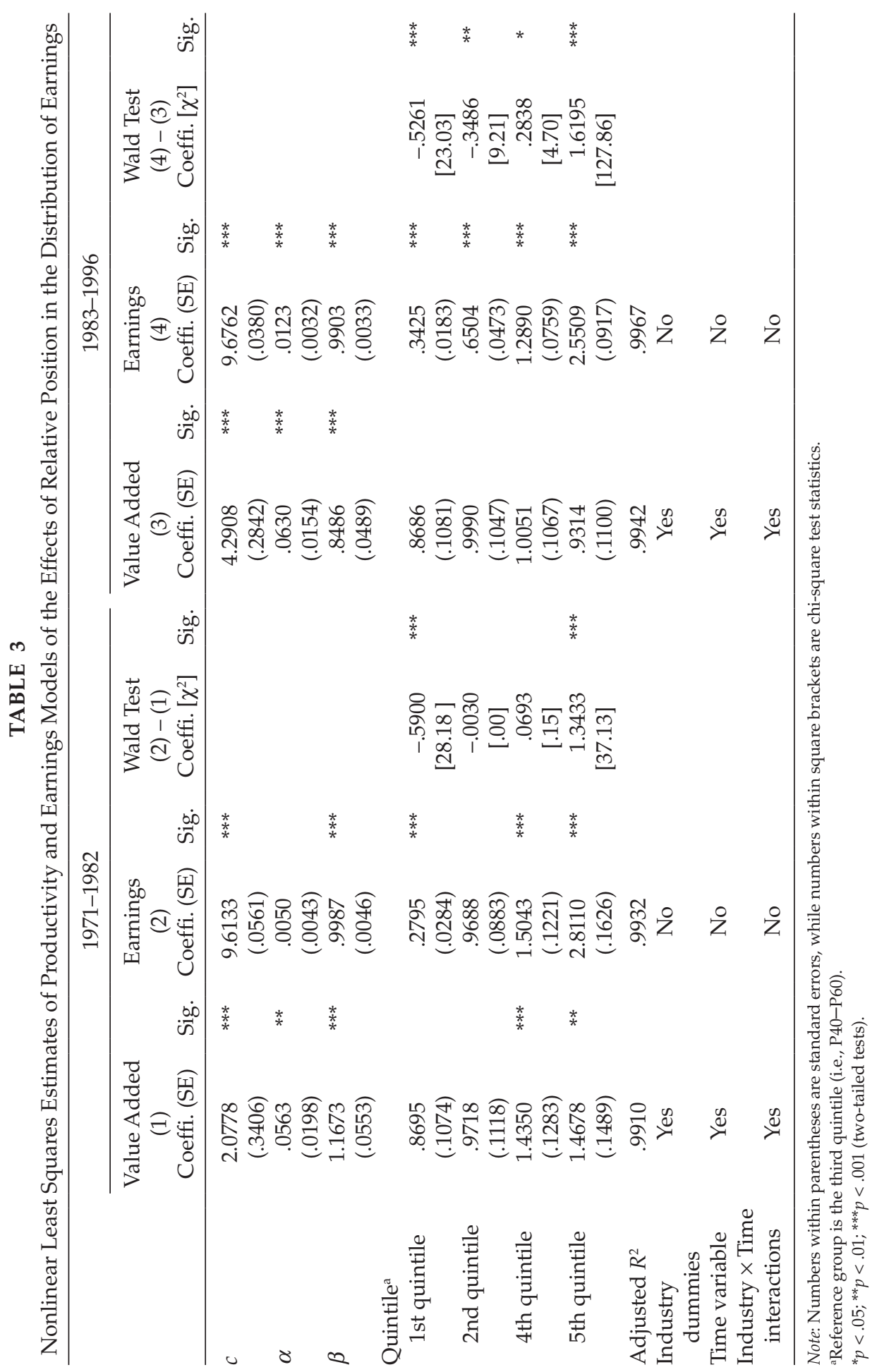


of several other labor market trends, including globalization, deregulation, the spread of computer technology, and the decline in union membership (Kim and Sakamoto 2008a).

As shown in Table 3, the results for the earlier period show that only the coefficients for the fourth and fifth quintiles are statistically significant in the productivity equation using these industrial-level data. Relative to the marginal productivity of workers in the omitted category, the marginal productivity of workers in the fourth and fifth quintiles are estimated to be 44 percent and 47 percent higher, respectively. Because the coefficients for the first and second quintiles are not statistically significant, we cannot confidently reject the hypothesis that the marginal productivities of workers in those quintiles are no different from workers in the third quintile.

In terms of the earnings function for the 1971 to 1982 period, Table 3 shows that all of the estimates of the $\zeta^{\prime}$ s are statistically significant, except for the second quintile. The coefficient of .28 for workers in the first quintile indicates that they earn 72 percent less than workers in the third quintile. On the other hand, the coefficients for the fourth and fifth quintiles indicate that those workers earn 50 percent and 181 percent more, respectively, than workers in the third quintile. For workers in the second quintile, the estimated coefficient is nearly unity and is not statistically significant, indicating that the proportion of employees in the second quintile does not clearly affect total earnings payments differently from the proportion of employees in the third quintile (because their earnings are so close during this time period).

In regard to exploitation during the earlier period, Table 3 shows that Wald chisquare tests are statistically significant for the first and fifth quintiles. For workers in the first quintile, the difference between their estimated $\delta$ (i.e., .87) and $\zeta$ (i.e., . 28) implies that they are underpaid by 59 percent, which is indicated in Table 3. For workers in the fifth quintile, their estimated $\delta$ (i.e., 1.47) is less than their estimated $\zeta$ (i.e., 2.81), implying that they are overpaid by 134 percent.

Table 3 shows that the Wald chi-square test for the difference between productivity and earnings is not statistically significant for workers in the second and fourth quintiles. For these two quintiles, their productivity and earnings differentials are approximately equal. The second quintile is about 3 percent lower than the third quintile in terms of productivity and earnings, whereas the differential for the fourth quintile is about 44 to 50 percent higher. Workers in the second and fourth quintiles are thus neither underpaid nor overpaid during the earlier period.

The results in Table 3 for the period 1983 to 1996 are somewhat different. In terms of the productivity equation, none of the estimated $\delta^{\prime}$ s is statistically significant. Most of the estimated $\delta^{\prime}$ s are close to unity. Earnings inequalities in the later period do not appear to be systematically associated with variations in marginal productivities at least when considered at the level of quintiles in the earnings distribution using these industrial-level data.

On the other hand, all of the estimated $\zeta^{\prime}$ ' in the earnings equation are statistically significant for the later period, as shown in Table 3 . These findings indicate that the quintile distribution across industries is clearly associated with total earnings payments to workers. Relative to the third quintile, earnings is 66 percent 
lower for the first quintile, 35 percent lower for the second quintile, 29 percent higher for the fourth quintile, and 155 percent higher for the fifth quintile.

These results imply high levels of exploitation in the 1983 to 1996 period. For the fifth quintile, the difference between its estimated $\delta$ and $\zeta$ indicates that this group is overpaid by 162 percent. For the fourth quintile, the overpayment amounts to 28 percent. The two exploited groups are the first and second quintiles that are unpaid by 53 percent and 35 percent, respectively. The Wald chi-square tests in Table 3 for this later period are statistically significant for each of these differentials.

Overall, the findings reported in Table 3 indicate that exploitation increased in the later period relative to the earlier period. In the period from 1971 to 1982, the statistical significance tests confirmed that only one quintile was clearly overpaid (i.e., the fifth) and only one quintile was undoubtedly underpaid (i.e., the first). In the period from 1983 to 1996, however, the statistical significance tests indicated that two quintiles were overpaid (i.e., the fourth and the fifth) while two quintiles were underpaid (i.e., the first and the second). Thus, exploitation increased in the later period because the second and fourth quintiles were no longer being paid according to their marginal productivities but instead had become either exploited or exploiting groups. Although the level of exploitation of the first quintile changed only slightly in the later period compared to the earlier period, the exploitative overpayment of the fifth quintile increased substantially from 134 percent to 162 percent (i.e., an increase of 28 percentage points).

To test the statistical significance of the change in the level of exploitation across these two time periods, we calculated a chi-square test statistic for the null hypothesis of no change. For each of the quintiles, the null hypothesis was rejected at the .10 level but not at the .05 level. At the .10 level, the increase in the estimated level of exploitation for the second quintile is statistically significant, while the increases in the level of overpayment for the fourth and fifth quintiles are statistically significant at that level as well. For the first quintile, the slight decline in the level of exploitation across the two time periods is statistically significant at the .10 level.

\section{DISCUSSION}

The two major parts of our analysis yield compatible results. In the first part, we investigated differentials across categories of employees. The findings indicate that women, Hispanics, African Americans, and blue-collar workers are substantially underpaid relative to their contributions to industrial productivity. In the second part, we found that the quintiles associated with higher levels of inequality do not always generate correspondingly higher levels of productivity. The fifth quintile was consistently overpaid, while the first quintile was consistently underpaid, which may be interpreted as exploitation by relative position in the distribution of earnings. Because women, Hispanics, African Americans, and blue-collar workers are more likely to be in lowest quintile and are less likely to be in the highest quintile, the conclusions from these two parts of our investigation are consistent with each other. 
Despite the obvious significance of ascribed factors in these findings, our results further indicate that exploitation is to some extent endemic in the distribution of earnings and is thus not limited to women and minorities. Table 2 shows, for example, that the rate of exploitation of blue-collar workers is quite high and approximately equal to the rate of exploitation of women. Although space limitations prevent us from providing a full descriptive analysis, the majority of our sample are non-Hispanic white males and almost two-thirds of them are employed in the blue-collar occupational category. Thus, a high level of appropriation is associated with non-Hispanic white males simply because they are the largest demographic group in the manufacturing sector, and they are mostly employed in blue-collar occupations that have a high rate of exploitation.

Regarding the trend in exploitation over time, our findings suggest that exploitation has been increasing in recent years. In the period from 1983 to 1996, the second quintile became an exploited group, while the fourth quintile became an exploiting group. Furthermore, the fifth quintile substantially increased its level of overpayment relative to the period before 1983. These changes in the rates of exploitation by quintile are significant at the .10 level (using a two-tailed test) and are not theoretically suspect.

This trend towards increasing exploitation may be interpreted in terms of Hirsch and De Soucey's (2006) discussion regarding the role of power in influencing the economic outcomes associated with organizational restructuring in recent years. Rather than reflecting only a rising organizational imperative for greater efficiency, the increased inequality that has occurred is at least partly a reflection of bargaining power differentials between workers. The decline in unions, the falling real value of the minimum wage, the increased number of part-time workers, and the dismantling of internal labor market practices have all increased inequality but may be less important to improving productivity than is usually assumed in popular discussions (Kim and Sakamoto 2008b). Rather than being necessary to improve productivity, rising inequality in the manufacturing sector may derive from the downgrading of the earnings of workers with the least bargaining power, who are often women, minorities, and other workers in blue-collar occupations or the lower two quintiles of the earnings distribution.

Critical actors in these trends are managers who are typically involved in decision making regarding personnel, promotions, and organizational restructuring. Our finding that managers are the only occupational category that is substantially overpaid relative to their productivity underscores their power in the New Economy (Hirsch and De Soucey 2006). The decline in the returns to firm tenure due to reduced earnings growth through internal labor markets (Cappelli 2001) suggests a waning of "bureaucratic control" (Edwards 1979) and the increased discretionary power of managerial authority (Gordon 1996).

Other results in Table 2 indicate that middle-aged workers (i.e., thirty-five to fifty-four years of age) and older workers (i.e., fifty-five or more years of age) are substantially overpaid and thus may be viewed as exploiters along with managers. Older workers may have greater personal influence in the firm due to greater seniority or organizational authority. They may have the power to affect decisionmaking processes in order to obtain wages that exceed their productivities. 


\section{CONCLUSION}

Dating back to the work of Karl Marx, the study of inequality has become a wellestablished subfield of sociology. Despite the continuing influence of the Marxist perspective on this area of research, however, contemporary sociologists have ironically abandoned the empirical analysis of exploitation, which had been central to Marx's concerns. In the foregoing, we have demonstrated that the objective investigation of exploitation is entirely feasible, is informative, and need not be eschewed by quantitative sociologists. As inequality continues to rise in the United States and elsewhere, empirical studies of exploitation are increasingly needed.

We have utilized the Weberian perspective to develop a measure that relies on market values given the embeddedness of the existing "market situation." This approach avoids the intractable methodological and theoretical limitations of both classical Marxism (which relies on the outdated labor theory of value) and Sørensen's rent-based analysis (which rests on the dubious notion of perfect market competition). Our methodology is not only amenable to empirical investigation using currently available data but is also able to identify a critical dimension of economic underpayment. Although a related study by Liu et al. (Forthcoming) also investigates patterns of economic underpayment and overpayment, their analysis does not directly link these phenomena to inequality in the distribution of earnings and how the level of inequality has been increasing in recent years. Liu et al. (Forthcoming) are furthermore focused on the case of Taiwan.

In conclusion, our broader research objective has been to promote further research and to encourage the development of a broader literature on the sociological study of exploitation. We do not argue that our measure represents the only conceivable definition. Social stratification research has often focused on describing mobility patterns, assessing how "who gets ahead" is associated with ascribed traits, detailing the sources of status attainment, and investigating how occupational structure relates to career outcomes. Inadequate attention has been devoted, however, to understanding the underlying nature of inequality in the overall distribution of scarce socioeconomic rewards. Our investigation has focused on the latter issue and has yielded empirical results that suggest the increasing exploitation of disadvantaged workers.

Acknowledgments: For helpful comments in this research, the authors thank the Editors, three anonymous reviewers, and the Fall 2006 Faculty Fellows of the Humanities Institute at the University of Texas.

\section{NOTES}

1. This analysis is unable to identify the underlying source of this gender differential, which may involve the segregation of women into less productive manufacturing firms, sextyping into detailed occupational titles, comparative worth processes, or unmeasured variables such as fewer years of accumulated labor force experience.

2. The statistical significance tests in Table 2 and Table 3 indicate whether the coefficients estimated for our labor force categories are significantly different from unity. The statistical significance tests of the constant, $\alpha$, and $\beta$ show whether they are significantly different from zero. 
3. Due to limited degrees of freedom, our specification does not include an interaction between marital status and gender.

\section{REFERENCES}

Autor, H. David, Lawrence F. Katz, and Melissa S. Kearney. 2006. "The Polarization of the U.S. Labor Market." American Economic Review 96:189-94.

Bertrand, Marianne and Sendhil Mullainathan. 2004. "Are Emily and Greg More Employable than Lakisha and Jamal? A Field Experiment on Labor Market Discrimination." American Economic Review 94:991-1013.

Budig, Michelle J. and Paula England. 2001. "The Wage Penalty for Motherhood." American Sociological Review 66:204-25.

Cappelli, Peter. 2001. "Assessing the Decline of Internal Labor Markets." Pp. 207-45 in Sourcebook of Labor Markets, edited by I. Berg and A. Kalleberg. New York: Kluwer Academic/Plenum Publishers.

Correll, Shelley, Stephen Benard, and In Paik. 2007. "Getting a Job: Is There a Motherhood Penalty?" American Journal of Sociology 112:1297-338.

Croson, Rachel and Uri Gneezy. 2009. "Gender Differences in Preferences." Journal of Economic Literature 47:448-74.

Dickens, William T. and Lawrence F. Katz. 1987. "Inter-Industry Wage Differences and Industry Characteristics." Pp. 48-89 in Unemployment and the Structure of Labor Markets, edited by K. Lang and J. S. Leonard. New York: Basil Blackwell.

Dietzenbacker, Erik, Michael L. Lahr, and Bart Los. 2004. “The Decline in Labor Compensation's Share of GDP: A Structural Decomposition Analysis for the United States, 1982 to 1997." Pp. 188-212 in Wassily Leontief and Input-Output Economics, edited by E. Dietzenbacker and M. Lahr. New York: Cambridge University Press.

Edwards, Richard C. 1979. Contested Terrain. New York: Basic Books.

England, Paula, Jennifer Thompson, and Carolyn Aman. 2001. "The Sex Gap in Pay and Comparable Worth: An Update." Pp. 551-65 in Sourcebook of Labor Markets Evolving Structures and Processes, edited by I. Berg and A. Kalleberg. New York: Kluwer Academic/Plenum Publishers.

Goldthorpe, John H. 2000. "Rent, Class Conflict, and Class Structure: A Commentary on Sørensen." American Journal of Sociology 105:1572-82.

Gordon, David M. 1996. Fat and Mean: The Corporate Squeeze of Working Americans and the Myth of Managerial "Downsizing." New York: The Free Press.

Grusky, David B. 2005. "Foundations of a Neo-Durkheimian Class Analysis." Pp. 51-81 in Approaches to Class Analysis, edited by E. O. Wright. New York: Cambridge University Press.

Hellerstein, Judith K., David Neumark, and Kenneth R. Troske. 1999. “Wages, Productivity, and Worker Characteristics: Evidence from Plant-Level Production Functions and Wage Equations." Journal of Labor Economics 17:409-46.

Hirsch, Peter M. and Michael de Soucey. 2006. "Organizational Restructuring and its Consequences: Rhetorical and Structural." Annual Review of Sociology 32:171-89.

Jacobs, Jerry A. 2001. "Evolving Patterns of Sex Segregation." Pp. 535-50 in Sourcebook of Labor Markets, edited by I. Berg and A. Kalleberg. New York: Kluwer Academic/ Plenum Publishers.

Johnson, Monica Kirkpatrick. 2005. “Family Roles and Work Values: Processes of Selection and Change." Journal of Marriage and the Family 67:352-69.

Kaufman, Robert L. 2001. "Race and Labor Market Segmentation." Pp. 645-68 in Sourcebook of Labor Markets, edited by I. Berg and A. Kalleberg. New York: Kluwer Academic/ Plenum Publishers. 
Kim, ChangHwan and Arthur Sakamoto. 2008a. "The Rise of Intra-Occupational Wage Inequality in the United States, 1983 to 2002." American Sociological Review 73:129-57.

- 2008b. "Does Inequality Increase Productivity? Evidence from U.S. Manufacturing Industries, 1979 to 1996." Work and Occupations 35:85-114.

_. 2008c. "Declining Inter-Industry Wage Dispersion in the U.S." Social Science Research 37:1081-101.

Liu, Jeng, Arthur Sakamoto, and Kuo-Hsien Su. Forthcoming. "An Empirical Analysis of Exploitation in Contemporary Capitalism: Some Evidence for Taiwan." Sociological Focus.

Marini, Margaret Mooney and Pi-Ling Fan. 1997. “The Gender Gap in Earnings at Career Entry." American Sociological Review 62:588-604.

Massey, Douglas S. and Nancy A. Denton. 1993. American Apartheid: Segregation and the Making of the Underclass. Cambridge, MA: Harvard University Press.

McKinnish, Terra. 2008. "Spousal Mobility and Earnings." Demography 45:829-49.

Murphy, Raymond. 1988. Social Closure. Oxford, UK: Clarendon Press.

Petersen, Trond and Linda A. Morgan. 1995. "Separate and Unequal-Occupation Establishment Sex Segregation and the Gender Wage Gap." American Journal of Sociology 101:329-65.

Piketty, Thomas and Emmanuel Saez. 2003. "Income Inequality in the United States, 19131998." Quarterly Journal of Economics 118:1-39.

Sakamoto, Arthur and Jeng Liu. 2006. "A Critique of Wright's Analysis of Exploitation." Research in Social Stratification and Mobility 24:209-21.

Sørensen, Aage B. 1977. "The Structure of Inequality and the Process of Attainment." American Sociological Review 42:965-78.

- 2000. "Toward a Sounder Basis for Class Analysis." American Journal of Sociology 105:1523-58.

Stolzenberg, Ross M. and Kenneth C. Land. 1983. "Causal Modeling and Survey Research." Pp. 613-75 in Handbook of Survey Research, edited by P. H. Rossi, J. D. Wright, and A. B. Anderson. New York: Academic Press.

Tomaskovic-Devey, Donald, Melvin Thomas, and Kecia Johnson. 2005. "Race and the Accumulation of Human Capital across the Career: A Theoretical Model and Fixed-Effects Application." American Journal of Sociology 111:58-89.

Weber, Max. [1922] 1978. Economy and Society, edited by G. Roth and C. Wittich. Berkeley: University of California Press.

Wright, Erik O. 2000. “Class, Exploitation, and Economic Rents: Reflections on Sørensen's 'Sounder Basis.'" American Journal of Sociology 105:1559-71. 

Reproduced with permission of the copyright owner. Further reproduction prohibited without permission. 